Check for updates

Cite this: RSC Adv., 2018, 8, 16044

Received 1st February 2018

Accepted 24th April 2018

DOI: $10.1039 / c 8 r a 01027 g$

rsc.li/rsc-advances

\section{Polydopamine-coated graphene nanosheets as efficient electrocatalysts for oxygen reduction reaction $\uparrow$}

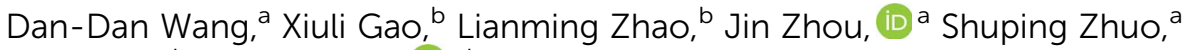 \\ Zifeng Yan $^{\mathrm{b}}$ and Wei Xing (D) *b
}

Polydopamine-modified graphene (G-PDA) materials were synthesized by in situ polymerization of a dopamine monomer on the surface of graphene oxide. X-ray photoelectron spectroscopy (XPS) has confirmed that new $\mathrm{N}$-containing functional groups are formed during the synthesis process, which result in the excellent electrocatalytic activity of the composite towards ORR in terms of onset potential, number of electron transferred and limiting current density. The electrocatalytic activity of the optimized G-PDA sample is better than $\mathrm{N}$-doped graphene and comparable to the commercial $20 \mathrm{wt} \% \mathrm{Pt} / \mathrm{C}$ catalyst. Furthermore, compared with the Pt-based catalysts, the G-PDA showed superior stability and methanol resistance, which favored its practical applications in fuel cells.

\section{Introduction}

The growing global energy demand and environmental pollution of traditional energy resources pose severe challenges to human health, energy regeneration, and environmental protection. ${ }^{1-4}$ One promising solution is fuel cell technology because of their high efficiency and environmental friendliness. It is well known that fuel cells require a catalyst for oxygen reduction reaction (ORR) in the cathode. Traditionally, platinum (Pt) has been identified as the best ORR catalyst. Whereas, the high cost, ${ }^{5,6}$ few reserves ${ }^{7}$ and weak durability ${ }^{8,9}$ of Pt seriously impede their large-scale applications. Thus, exploring non-precious metals or even metal free catalysts is highly desirable.

Actually, many studies have demonstrated that heteroatomdoping can effectively enhance ORR activity of carbon. Those heteroatoms include nitrogen, ${ }^{10-14}$ boron, ${ }^{15,16}$ sulfur, ${ }^{17,18}$ phosphorous $^{19,20}$ and their mixtures. ${ }^{21-23}$ Among these heteroatomdoped carbons, the nitrogen-doped carbon materials, such as nitrogen-doped graphene, ${ }^{24-26}$ nitrogen-doped nanotubes ${ }^{27,28}$ and nitrogen-doped carbon spheres, ${ }^{29,30}$ have been mostly investigated due to their easy preparation and high ORR activity. ${ }^{31}$ For example, Zhang et al. prepared the N-doped mesoporous graphene by a chemical vapor deposition (CVD) using $\mathrm{CH}_{4}$ and $\mathrm{NH}_{3}$ as the carbon source and nitrogen source,

${ }^{a}$ School of Chemical Engineering, Shandong University of Technology, Zibo 255049, P. R. China

${ }^{b}$ School of Science, State Key Laboratory of Heavy Oil Processing, China University of Petroleum, Qingdao 266580, P. R. China. E-mail: xingwei@upc.edu.cn

$\dagger$ Electronic supplementary information (ESI) available. See DOI: $10.1039 / \mathrm{c} 8 \mathrm{ra} 01027 \mathrm{~g}$ respectively. The prepared N-doped graphene exhibited superior ORR activity with onset potential of $0.81 \mathrm{~V} v s$. RHE to its counterpart without N-doping of $0.76 \mathrm{~V}^{32}$ Ruoff et al. prepared nitrogen-doped graphene by annealing of polyaniline or polypyrrole/reduced graphene oxide composite. The product displays an onset potential of up to $-0.18 \mathrm{~V} v s$. $\mathrm{Ag} / \mathrm{AgCl}$, which is a little bit smaller than that of $20 \% \mathrm{Pt} / \mathrm{C} .{ }^{33}$ Wong et al. prepared $\mathrm{N}$-doped graphene by thermal annealing graphene oxide with melamine. The results show that the ORR undergo by a one-step four-electron pathway, and the onset potential is up to $-0.10 \mathrm{~V}$ vs. $\mathrm{Ag} / \mathrm{AgCl}$ that is comparable to that of $20 \mathrm{wt} \% \mathrm{Pt} / \mathrm{C}(-0.03 \mathrm{~V}$ vs. $\mathrm{Ag} / \mathrm{AgCl}) .{ }^{34}$ Chen et al. synthesized nitrogen-doped carbon nanotubes (N-CNT) by a CVD method using ethylenediamine as nitrogen source. The half-wave potential of the N-CNT is $-0.15 \mathrm{~V} v s . \mathrm{Ag} / \mathrm{AgCl}$ and the limiting current density is -4.91 $\mathrm{mA} \mathrm{cm}{ }^{-2}$, which are similar to those of the commercial Pt/C catalyst. ${ }^{35}$ Wang et al. prepared pyridinic nitrogen-rich carbon nanospheres by direct annealing of polydopamine derivative. The product shows superior ORR activity with a onset potential of $0.98 \mathrm{~V}$ and a high half-wave potential of $0.88 \mathrm{~V}$, which are comparable to the $20 \mathrm{wt} \% \mathrm{Pt} / \mathrm{C} .{ }^{36} \mathrm{Up}$ to date, the N-containing carbonaceous ORR catalysts reported previously are all $\mathrm{N}$ doped carbons, where the $\mathrm{N}$ atoms exist in the carbon lattice. Besides, most the $\mathrm{N}$-doped carbon catalysts were prepared by high energy-consuming processes, such as chemical vapor deposition $^{37}$ in the presence of a nitrogen source, thermal annealing with ammonia ${ }^{38}$ or pyrolysis of a nitrogen-containing precursor (such as melamine, polypyrrole, and pyridine) (39-41 $^{39}$ high temperatures.

Herein, we propose a novel polydopamine (PDA)/graphene catalyst with high performance towards ORR by in situ polymerization of dopamine monomer on the surface of graphene 
oxide. This catalyst distinguished itself with the previous $\mathrm{N}$ doped carbon catalysts in the following two points: (1) the $\mathrm{N}$ atoms in the catalyst do not exist in the carbon lattice, but in the polymer (polydopamine); (2) the preparation avoids annealing or pyrolysis at high temperatures, which is a quite energy-saving process. Electrochemical measurements show that the optimized PDA/graphene composite has better catalytic activity towards ORR than $\mathrm{N}$-doped graphene and comparable to the commercial $20 \mathrm{wt} \% \mathrm{Pt} / \mathrm{C}$ catalyst. Furthermore, compared with the Pt-based catalysts, the composite catalyst shows superior stability and methanol resistance, which highlights its practical applications in fuel cells.

\section{Experimental methods}

\subsection{Materials and apparatus}

Flake graphite and potassium hydroxide (KOH) was obtained from Sinopharm Chemical Reagent. Dopamine hydrochloride (98\%) and Tris(hydroxylmethyl) aminomethane hydrochloride (Tris-HCl, 99\%) were purchased from Aladdin Chemical Reagent. The commercial Pt/C $20 \mathrm{wt} \%$ was obtained from Johnson Matthey Co. Ltd, which is commonly used as a standard in the ORR test. All reagents were of analytical grade and used as received without further purification. Deionized water was used as solvent for all experiments.

Morphology of the samples was observed by field-emission scanning electron microscope (SEM, JEOL JSM-6700F). X-ray diffraction (XRD) measurements were obtained on a D/Max $2500 \mathrm{~V} / \mathrm{PC}$ diffractometer using $\mathrm{Cu} \mathrm{K} \alpha$ radiation with wavelength of $0.15405 \mathrm{~nm}$. The surface chemical state of the samples was measured by X-ray photoelectron spectroscopy (XPS, ESCALAB MK II VG Co., UK) using Al K $\alpha$ radiation. Fourier transform infrared (FTIR) spectra were recorded on a Hitachi EPI Infrared Spectrophotometer using a $\mathrm{KBr}$ disk with an active material/KBr mass ratio of $1: 50$. Raman spectra were conducted on a confocal laser micro Raman spectrometer (LABRAM-HR, JY Co.).

\subsection{Preparation of graphene oxide aerogel (GOA)}

The graphite oxide was prepared according to the modified Hummer's method. ${ }^{42,43}$ The graphene oxide hydrogel was prepared according to Worsley's method. ${ }^{44}$ In a typical synthesis, the graphite oxide was dispersed in deionized water and sonicated to get homogeneous suspension of graphene oxide $\left(2 \mathrm{mg} \mathrm{mL}^{-1}\right)$. The suspension was then aged at $85{ }^{\circ} \mathrm{C}$ for $72 \mathrm{~h}$. The resulting graphene hydrogel was washed with deionized water for several times to remove impurities and then lyophilized to obtain GOA.

\subsection{Preparation of PDA/graphene composite}

The PDA/graphene composite was prepared by using the following procedure: $40 \mathrm{mg}$ of graphite oxide was dispersed in deionized water and the suspension was dispersed by sonication for $30 \mathrm{~min}\left(2 \mathrm{mg} \mathrm{mL} \mathrm{m}^{-1}\right)$. Then a certain amount of dopamine hydrochloride was added and the mixture was stirred at room temperature for $30 \mathrm{~min}$. Subsequently, $15 \mu \mathrm{L}$ of Tris- $\mathrm{HCl}$ solution
$(\mathrm{pH}=8.5)$ was added and the mixture was stirred vigorously at room temperature for another $30 \mathrm{~min}$, and then aged at $85^{\circ} \mathrm{C}$ for $72 \mathrm{~h}$. The obtained product was washed with deionized water several times to remove impurities and then the wet hydrogel was lyophilized. The dried product is designated as G-PDA- $m$, where $m$ represents the concentration of dopamine in the solution. For example, G-PDA- 0.5 denotes that the composite is prepared in the dopamine solution with concentration of $0.5 \mathrm{mg} \mathrm{mL}^{-1}$.

For comparison, G-PDA-1 was also carbonized at different temperatures in Ar atmosphere, and the carbonized products are denoted as C-G-PDA- $t$, where $t$ represents the carbonization temperature.

\subsection{Electrochemical measurements}

The preparation of the working electrode was as follows: $1 \mathrm{mg}$ of active material was added into $0.68 \mathrm{~mL}$ of deionized water, $0.3 \mathrm{~mL}$ of ethanol and $20 \mu \mathrm{L}$ of $5 \mathrm{wt} \%$ Nafion solution, which was dispersed by ultrasonication for $30 \mathrm{~min}$ to obtain a homogeneous suspension. Subsequently, $5.65 \mu \mathrm{L}$ of this suspension was transferred onto a rotating disk electrode to be fully dried.

The ORR activity of all samples was tested in a conventional three-electrode cell using a CHI 760E electrochemical workstation (Shanghai Chenhua Instrument Co., China) equipped with a rotating electrode setup. $\mathrm{Ag} / \mathrm{AgCl}$ electrode and $\mathrm{Pt}$ wire were used as the reference electrode and counter electrode, respectively. The RDE (rotating disk electrode) and rotating ring disk electrode (RRDE) measurements were obtained in an $\mathrm{O}_{2}$-saturated $0.1 \mathrm{M} \mathrm{KOH}$ aqueous solution at a scan rate of $10 \mathrm{mV} \mathrm{s}^{-1}$ with various rotation speeds (400-2500 rpm).

In the process of oxygen catalytic reduction, the electron transfer number $(n)$ and kinetic current density $\left(J_{\mathrm{k}}\right)$ were calculated according to the Koutecky-Levich (K-L) equation:

$$
\begin{gathered}
\frac{1}{j}=\frac{1}{j_{\mathrm{k}}}+\frac{1}{B \omega^{1 / 2}} \\
B=0.2 n F C_{\mathrm{o}}\left(D_{\mathrm{o}}\right)^{2 / 3} v^{-1 / 6}
\end{gathered}
$$

where $j$ is the measured current density, $j_{\mathrm{k}}$ is the kinetic current density, $\omega$ is the electrode rotation rate, $F$ is the Faraday constant (96485 $\left.\mathrm{C} \mathrm{mol}^{-1}\right), C_{\mathrm{o}}$ is the bulk concentration of $\mathrm{O}_{2}$ $\left(1.2 \times 10^{-6} \mathrm{~mol} \mathrm{~cm}^{-3}\right), D_{\mathrm{o}}$ is the diffusion coefficient of $\mathrm{O}_{2}(1.9$ $\left.\times 10^{-5} \mathrm{~cm}^{2} \mathrm{~s}^{-1}\right)$, and $\nu$ is the kinetic viscosity of the electrolyte $\left(0.01 \mathrm{~cm}^{2} \mathrm{~s}^{-1}\right)$. Here, the constant 0.2 is adopted when the rotating rate is expressed in rpm.

Hydrogen peroxide yields and the number of transferred electrons were calculated using the following equation:

$$
\mathrm{n}=4 \frac{I_{\mathrm{D}}}{I_{\mathrm{D}}+\frac{I_{\mathrm{R}}}{N}}
$$

$$
\mathrm{H}_{2} \mathrm{O}_{2} \%=200 \frac{\frac{I_{\mathrm{R}}}{N}}{I_{\mathrm{D}}+\frac{I_{\mathrm{R}}}{N}}
$$


where the collection efficiency $(N)$ was determined to be 0.412 in an $\mathrm{Ar}$ atmosphere using $10 \mathrm{mM} \mathrm{K}_{3}\left[\mathrm{Fe}(\mathrm{CN})_{6}\right]$.

\section{Results and discussion}

\subsection{Morphology and structure of G-PDA- $m$ materials}

The morphology of the as-prepared G-PDA- $m$ were observed by SEM. As shown in Fig. 1a, GOA shows three-dimensional network structure with gauzy and folded graphene sheets cross-linked with each other. With the presence and increase of PDA, the corrugated nanosheets become flat gradually possibly due to the presence of the PDA that is adsorbed on the surface of graphene oxide (Fig. 1b-d). However, when there is too much PDA present, the aggregation of G-PDA nanosheets occurs, as is shown in Fig. 1e and f.

X-ray diffraction (XRD) was conducted to investigate the crystal structure of the prepared samples (Fig. 2). A sharp peak at $2 \theta=10^{\circ}$ was assigned to the [002] plane of GO with a dspacing of $0.95 \mathrm{~nm}$ (Fig. 2a). After the addition of the dopamine, the peak $\left(2 \theta=9.3^{\circ}\right)$ decreased observably and a new broad diffraction peak $\left(2 \theta=25^{\circ}\right)$ with an interlayer spacing of $(\sim 0.356 \mathrm{~nm})$ appeared, corresponding to the [002] plane of graphite (Fig. 2b).

This means that GO are partially reduced to rGO during the polymerization of dopamine. As the increase amount of dopamine, the intensity of peak at $2 \theta=9.3^{\circ}$ was decreasing and the peak at $2 \theta=25^{\circ}$ was increasing gradually, indicating that more dopamine dosage results in deeper reduction of GO. At the same time, the peak $\left(2 \theta=9.3^{\circ}\right)$ becomes very broad, and shifts to higher angles with increasing dopamine. This is because the oxygen-functional groups in the interlayer spacing was gradually removed in the process of GO reduction. ${ }^{45,46}$

Fourier transform infrared (FTIR) spectroscopy was used to reveal the functional groups contained in the as-prepared materials. As shown in Fig. 3a, the GOA showed typical bands (a)
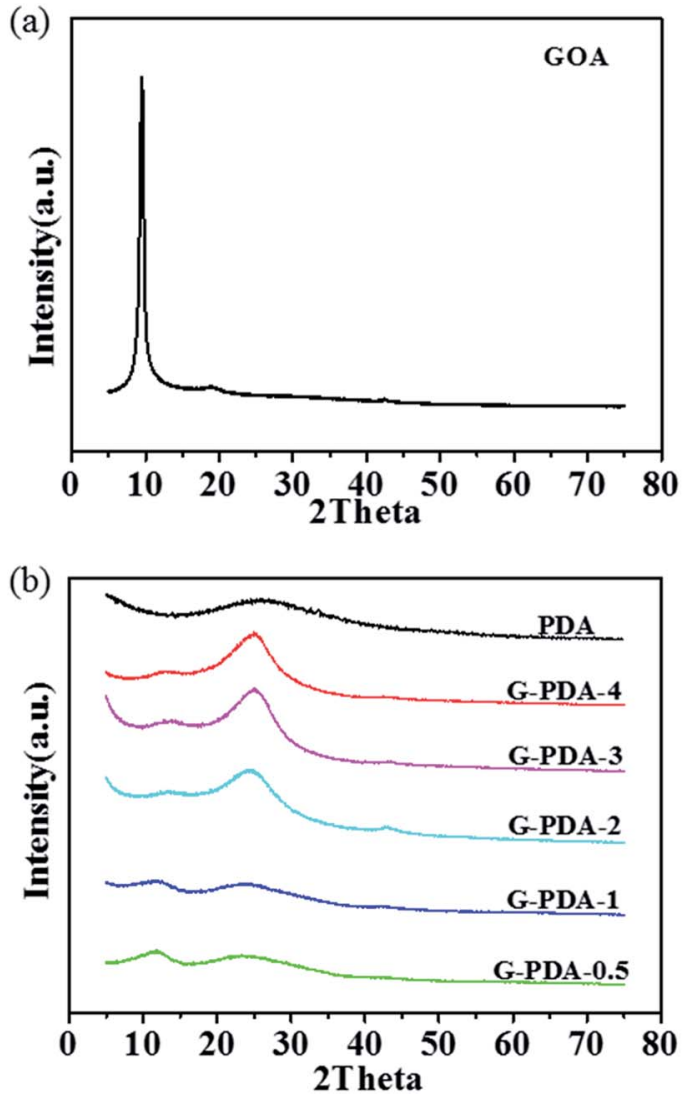

Fig. 2 XRD patterns of (a) GOA and (b) G-PDA- $m$ and PDA products.

at $1450,1666,1600$ and $1080 \mathrm{~cm}^{-1}$, which were attributed to the aromatic $\mathrm{C}=\mathrm{C}$ stretching, $\mathrm{C}=\mathrm{O}$ carboxyl stretching, asymmetric and symmetric C-O stretching, respectively. The bands at 2943 and $2826 \mathrm{~cm}^{-1}$ were attributed to the stretching vibration of $\mathrm{C}-\mathrm{H}$, which may be formed by the combination of proton
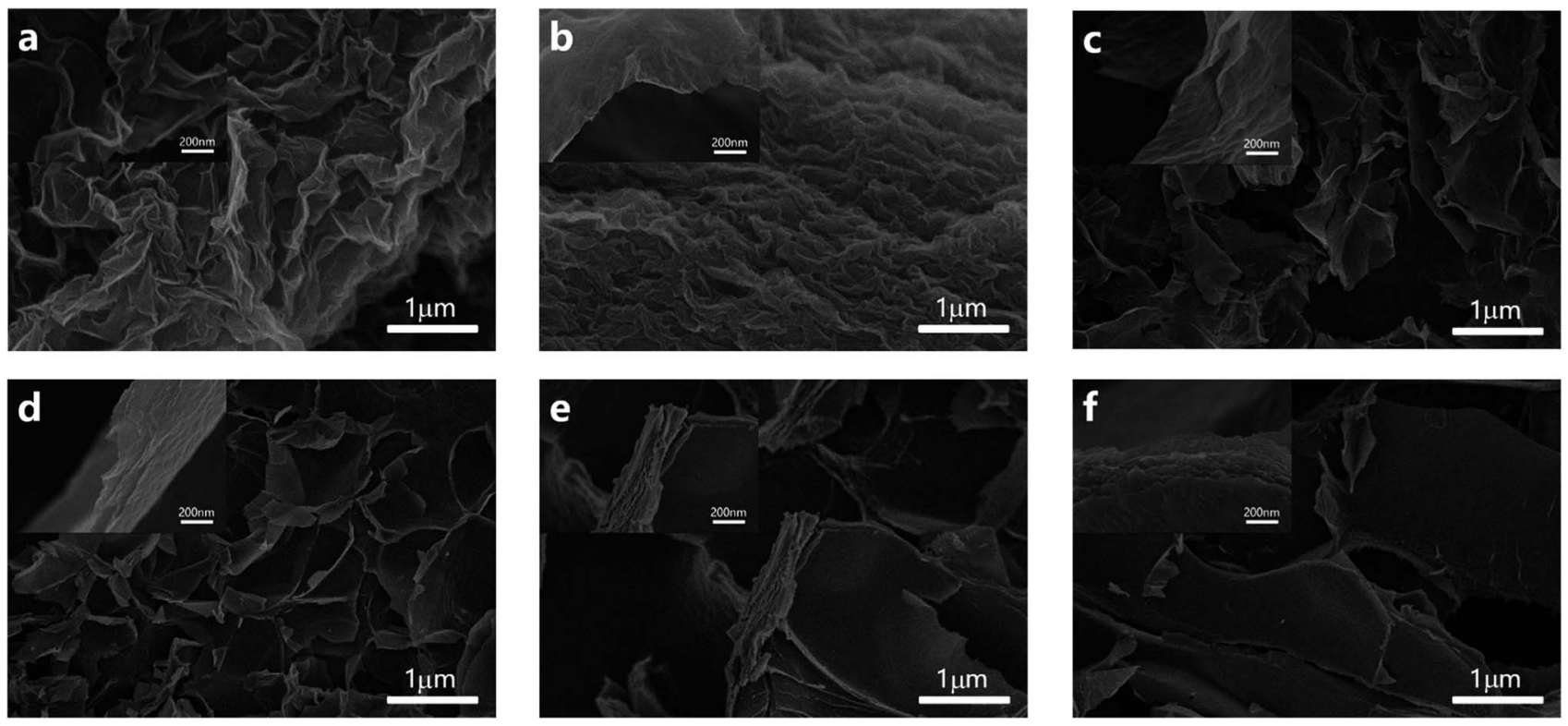

Fig. 1 SEM images of (a) GOA, (b) G-PDA-0.5, (c) G-PDA-1, (d) G-PDA-2, (e) G-PDA-3, (f) G-PDA-4 

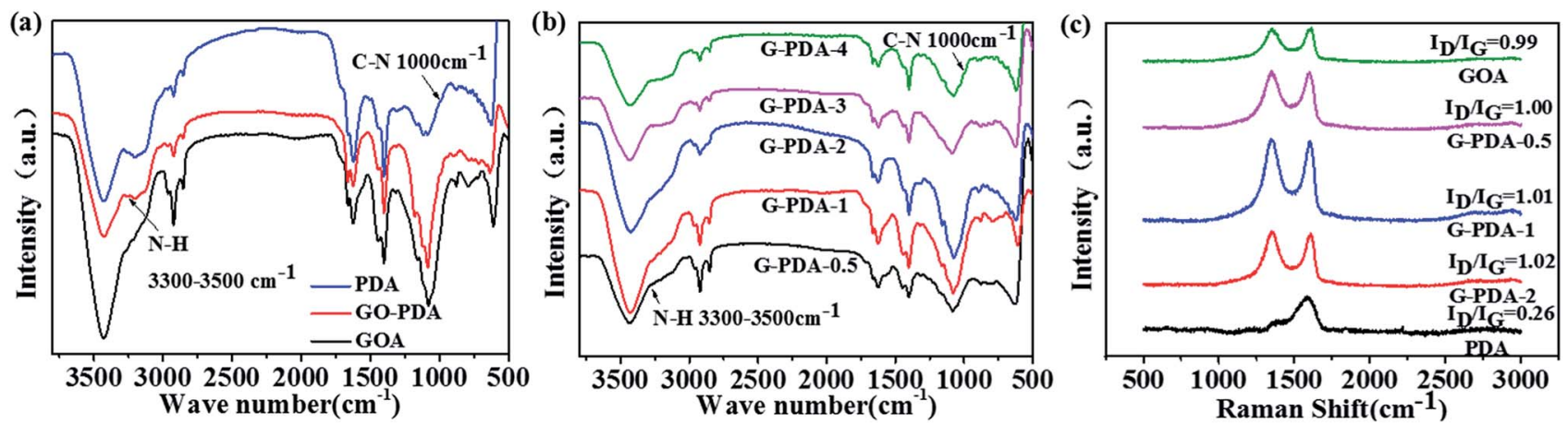

Fig. 3 FTIR analyses of the (a) PDA, G-PDA-1 and GOA and (b) G-PDA-m; (c) Raman analyses of the PDA, G-PDA- $m$ and GOA.

$\left(\mathrm{H}^{+}\right)$and carbon defects on the edge of graphene during the hydrothermal process. ${ }^{47}$ For G-PDA nanocomposites, the same bands could be found, and two new-bands occur at $1000 \mathrm{~cm}^{-1}$ and $3260 \mathrm{~cm}^{-1}$, which are due to the $\mathrm{C}-\mathrm{N}$ and $\mathrm{N}-\mathrm{H}$ groups in the PDA. The above information suggest the successful combination of PDA and GO. Comparing the as-prepared catalysts with different PDA/GO mass ratio, its easy to found that the curves are similar, and the bands due to $\mathrm{C}-\mathrm{N}$ and $\mathrm{N}-\mathrm{H}$ stretching vibrations became stronger with the increase of PDA content (Fig. 3b).
The Raman spectra are commonly used to reveal the structure of carbon skeleton in the materials. As shown in Fig. 3c, the two typical peaks at approximate $1354 \mathrm{~cm}^{-1}$ and $1600 \mathrm{~cm}^{-1}$ are consistent with the characteristic D and G bands, respectively, for the GOA. The D band was associated with structural defects and partially disordered structures on the graphene nanosheets. The $\mathrm{G}$ band, as an index of the degree of graphitization, is in connection to the $\mathrm{E}_{2 \mathrm{~g}}$ vibration mode of $\mathrm{sp}^{2}$ carbon domains. Generally, the intensity ratio of the $\mathrm{D}$ band to $\mathrm{G}$ band $\left(I_{\mathrm{D}} / I_{\mathrm{G}}\right)$ is used to evaluate the degree of defects for graphenebased materials. In contrast, D band is almost invisible and G
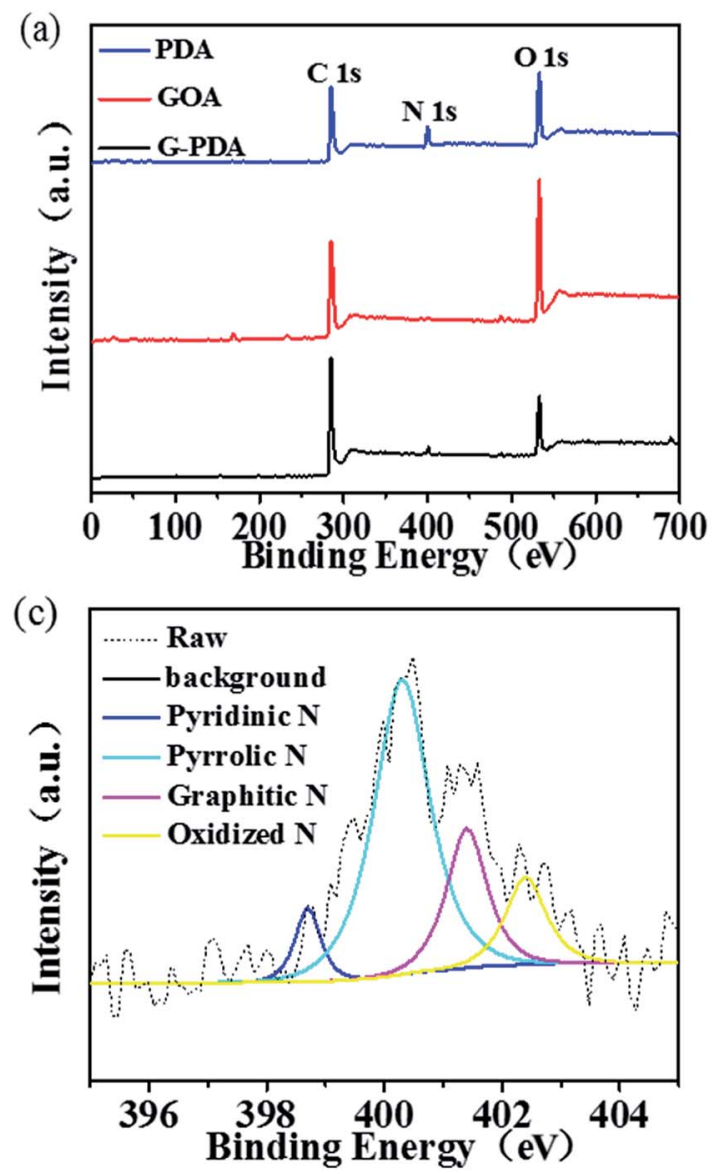
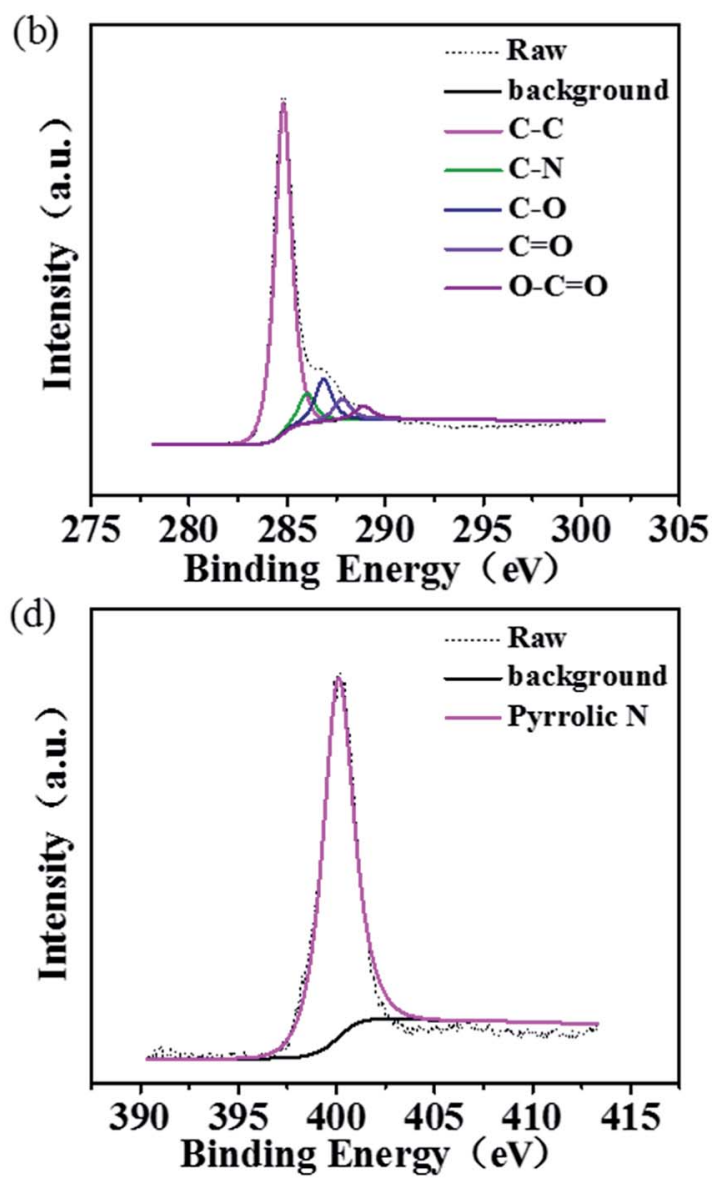

Fig. 4 (a) XPS spectra of GOA, PDA and G-PDA-1; (b) C 1s of G-PDA-1; (c) N 1s of G-PDA-1 (d) N 1s of PDA. 

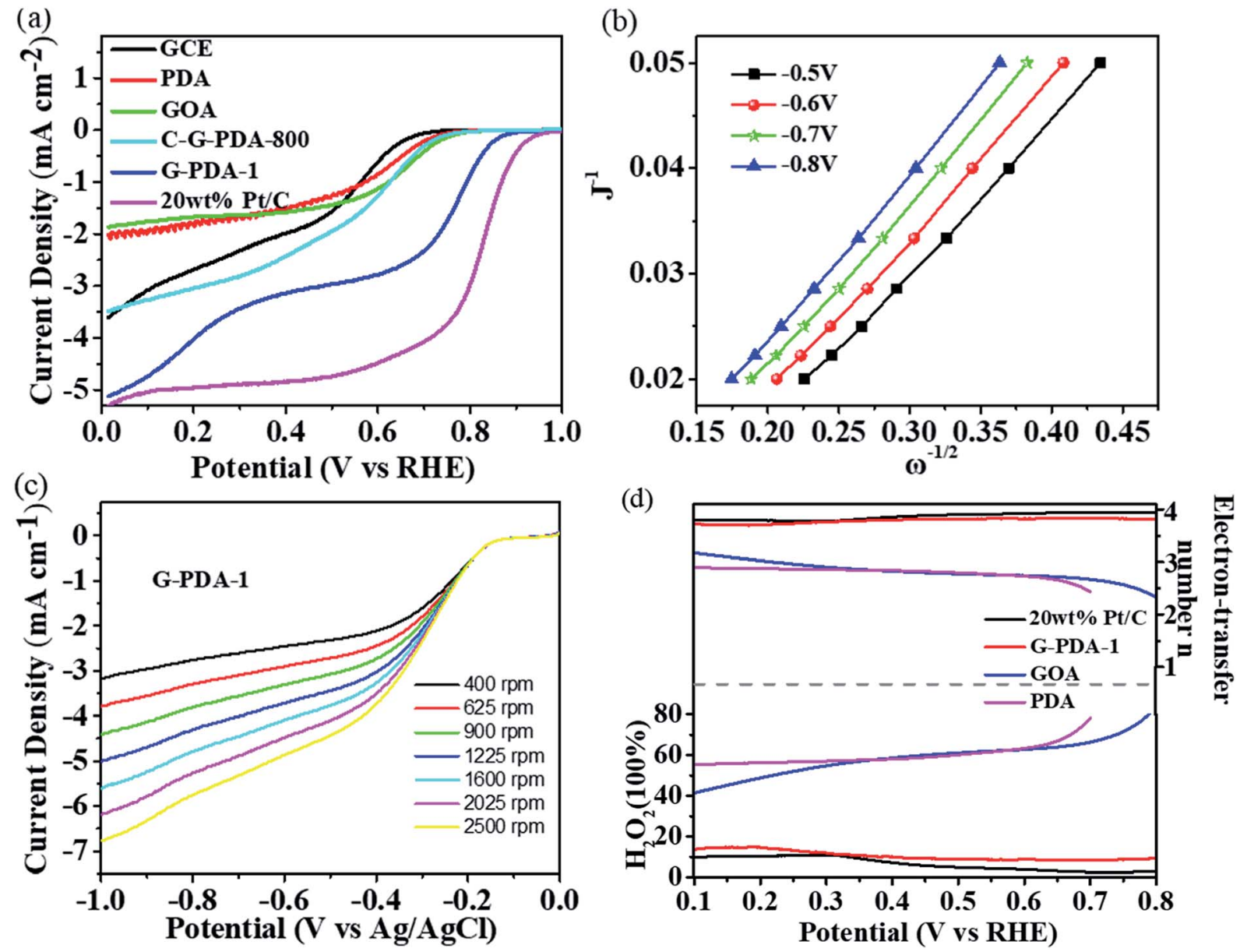

Fig. 5 (a) LSV curves for G-PDA-1, C-G-PDA-800, GOA, PDA and 20 wt\% Pt/C in $\mathrm{O}_{2}$-saturated $0.1 \mathrm{M} \mathrm{KOH}$ solution at a scan rate of $10 \mathrm{mV} \mathrm{s}^{-1}$; (b) the corresponding Koutecky-Levich plots at different potentials; (c) the rotating-disk voltammograms of G-PDA-1 in $\mathrm{O}_{2}$-saturated $0.1 \mathrm{M}$ KOH with a sweep rate of $10 \mathrm{mV} \mathrm{s}^{-1}$ at various rotation speeds; (d) electron-transfer numbers and $\mathrm{H}_{2} \mathrm{O}_{2}$ yields of G-PDA-1, GOA, PDA and 20 wt\% Pt/C with a rotation rate of $1600 \mathrm{rpm}$.

band is prominent for PDA, indicating that most carbon atoms in PDA are $\mathrm{sp}^{2}$ carbon. Of special interest is the fact that $I_{\mathrm{D}} / I_{\mathrm{G}}$ of G-PDA (1.00-1.02) was higher than that of GOA (0.99), suggesting that PDA may strongly interact with GO in the composite and induce more carbon defects.

The surface chemical composition and elemental chemical state of the as-prepared samples were characterized by XPS. As shown in Fig. 4a, $\mathrm{C}$ and $\mathrm{O}$ elements were present in all the three samples of GOA, PDA and G-PDA-1, but $\mathrm{N}$ element only existed in the G-PDA-1 and PDA but not in GOA, confirming the successful combination of PDA and GO using in situ polymerization of dopamine. The C1s spectrum of G-PDA-1 (Fig. 4b) can be deconvolved into five peaks with binding energies at about 284.8, 286.0, 286.8, 287.8 and $288.9 \mathrm{eV}$, corresponding to C-C, $\mathrm{C}-\mathrm{N}, \mathrm{C}-\mathrm{O}, \mathrm{C}=\mathrm{O}$, and $\mathrm{O}-\mathrm{C}=\mathrm{O}$ species, respectively. The $\mathrm{N} 1 \mathrm{~s}$ spectrum of G-PDA-1 (Fig. 4c) can be deconvolved into four peaks at about 398.7, 400.3, 401.4 and $402.4 \mathrm{eV}$, attributable to pyridinic $\mathrm{N}(6.84 \%)$, pyrrolic $\mathrm{N}(59.8 \%)$, graphitic $\mathrm{N}(20.51 \%)$ and oxidized $\mathrm{N}(12.82 \%)$, respectively. In contrast, the N1s spectrum of PDA showed only one peak at about $400.3 \mathrm{eV}$, which is attributed to the pyrrolic $\mathrm{N}$ (Fig. 4d). Combined with the results of Raman analyses, it can be deduced that the strong interaction between GO and PDA generated both carbon defects and various types of $\mathrm{N}$-containing functional groups that may show activity towards ORR.

\subsection{Electrocatalytic activity of the as-prepared samples towards ORR}

The catalytic activity of the samples towards ORR was assessed by linear sweep voltammograms (LSV) in $\mathrm{O}_{2}$-saturated $0.1 \mathrm{M}$ $\mathrm{KOH}$ solution at a scan rate of $10 \mathrm{mV} \mathrm{s}^{-1}$ between 0 and $+1.0 \mathrm{~V}$ vs. RHE. For comparison, the LSVs of different catalysts with a rotation rate of $1600 \mathrm{rpm}$ were shown in Fig. 5a, Fig. S1 and $\mathrm{S} 2 . \dagger$ According to limiting current densities, the onset potential for G-PDA-1 was around $+0.88 \mathrm{~V} v s$. RHE, which was higher than the pure GOA $(+0.74 \mathrm{~V} v s$. RHE), PDA $(+0.74 \mathrm{~V} v s$. RHE) and C-GPDA-800 $(+0.76 \mathrm{~V}$ vs. RHE), but still lower than $20 \mathrm{wt} \% \mathrm{Pt} / \mathrm{C}$ $(+0.96 \mathrm{~V} v s$. RHE). Moreover, G-PDA-1 displayed the most positive half-wave potential (the potential at which the current is half of the limiting current) among all the other samples prepared, and is almost the same as the $20 \mathrm{wt} \% \mathrm{Pt} / \mathrm{C}$, further confirming that the G-PDA-1 had excellent electrocatalytic 
(a)
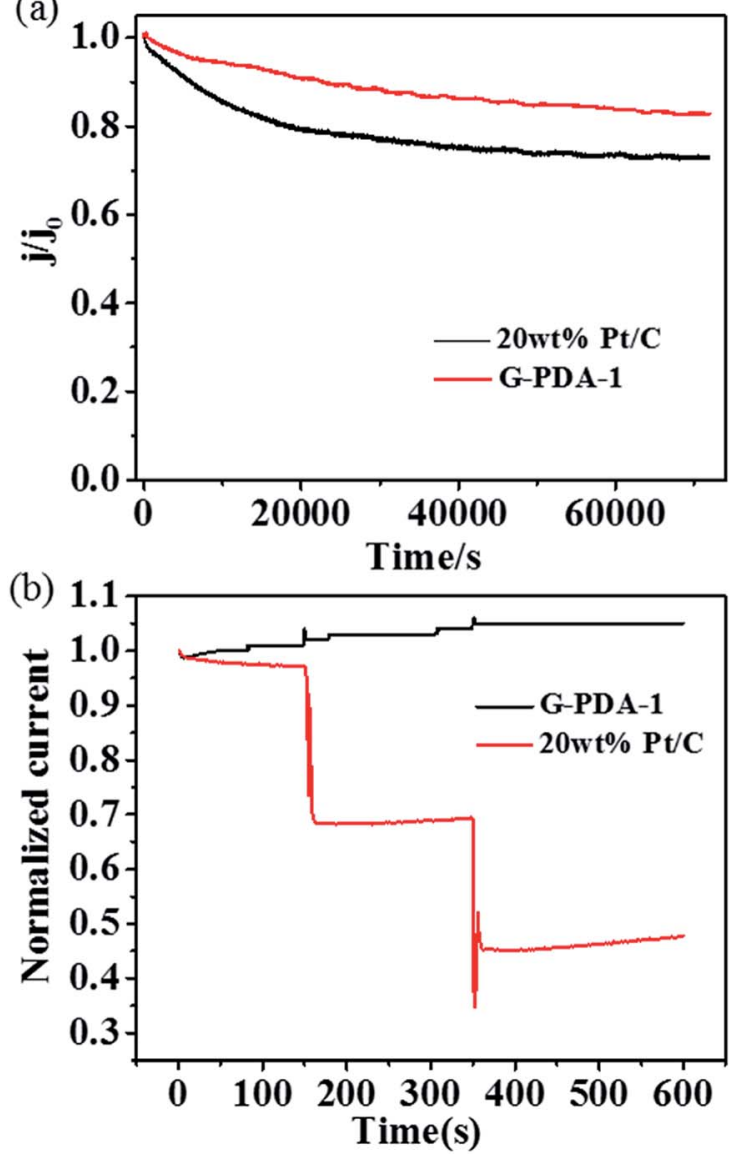

Fig. 6 (a) Stability test of G-PDA-1 and $20 \mathrm{wt} \% \mathrm{Pt} / \mathrm{C}$ catalyst for $70000 \mathrm{~s}$, (b) methanol crossover test by addition of methanol to the electrochemical cell at $150 \mathrm{~s}$ and $350 \mathrm{~s}$

activity towards ORR. The possible interpretation for the outstanding electrochemical performance of G-PDA-1 is mainly because of the carbon defects and various types of $\mathrm{N}$-containing functional groups. The defects change the charge density, resistance in charge transfer, and hydrophilicity of the composite, which may increase its electrical conductivity and interaction with oxygen.$^{48}$ Moreover, the various types of $\mathrm{N}$ containing functional groups will provide more active sites for ORR..$^{2,49}$

To further research the oxygen reduction process occurred on G-PDA-1, LSV measurements were carried out at various rotation speeds in $\mathrm{O}_{2}$-saturated $0.1 \mathrm{M} \mathrm{KOH}$ solution. As shown in Fig. $6 \mathrm{~b}$ and c, the Koutecky-Levich (K-L) plots $\left(\mathrm{J}^{-1}\right.$ vs. $\left.\omega^{-1 / 2}\right)$ of G-PDA- 1 at various potentials were given. Accordingly, the electron transfer number $(n)$ is calculated to be 4.07 . The $\mathrm{H}_{2} \mathrm{O}_{2}$ yield and the electron transfer number $(n)$ calculated from the RRDE curves are presented in Fig. 5d. The measured $\mathrm{H}_{2} \mathrm{O}_{2}$ yields are around $10 \%$ over the entire potential range of 0.1 to $0.8 \mathrm{~V} v s$. RHE for the G-PDA- 1 catalyst. This value is significantly lower than that of the GOA or PDA catalyst, which is near $80 \%$, and the electron transfer number was about 3.74-3.9 that is close to a commercial $\mathrm{Pt} / \mathrm{C}$ catalyst $(n=3.78-3.94)$. This is consistent with the result obtained from the $\mathrm{K}-\mathrm{L}$ plot based on the RDE measurements, indicating that G-PDA-1 favors a $4 \mathrm{e}^{-}$ oxygen reduction process, while GOA electrode involves a $2 \mathrm{e}^{-}$ reduction process with $\mathrm{H}_{2} \mathrm{O}_{2}$ as the intermediate agent. ${ }^{50}$

Based on the above results, we can conclude that G-PDA-1 possessed excellent electrocatalytic activity towards ORR, which can be ascribed to the following three reasons: (1) the strong interactions between GO and PDA induced the carbon defects and a variety of N-containing active sites for ORR; (2) the large surface of G-PDA nanosheets will further increase the catalytically active sites; (3) the intimate contact between GO and PDA facilitates charge-transfer, and the good conductivity of partially-reduced GO substrate facilitates electron transport.

In addition, the durability of G-PDA- 1 and $20 \mathrm{wt} \% \mathrm{Pt} / \mathrm{C}$ was measured by holding them at $+0.67 \mathrm{~V} v s$. RHE for $70000 \mathrm{~s}$ in $\mathrm{O}_{2}$ saturated 0.1 M KOH solution (Fig. 6a). Compared with $20 \mathrm{wt} \%$ $\mathrm{Pt} / \mathrm{C}$, the chronoamperometric response for the G-PDA-1 exhibited much slower decay. After reaction for $70000 \mathrm{~s}$, GPDA-1 still maintains $83 \%$ of its initial current density, which surpasses $20 \mathrm{wt} \% \mathrm{Pt} / \mathrm{C}$ of about $73 \%$. Unambiguously, the GPDA-1 also has an excellent stability in alkaline solution, which highlights its great potentials in alkaline fuel cells. It is thought that the combination of PDA and graphene also enhanced the material's mechanical stability, which may contribute to its excellent electrocatalytic stability. ${ }^{51}$

Because methanol tolerance of cathode catalyst is the one of the major evaluating factor for direct methanol fuel cell (DMFC), chronoamperometry was used to characterize methanol tolerance of the catalysts at a constant voltage of $0.67 \mathrm{~V} v s$. RHE in $\mathrm{O}_{2}$-saturated $0.1 \mathrm{M} \mathrm{KOH}$ aqueous solution (Fig. 6b). Obviously, after addition of methanol at $150 \mathrm{~s}$ and $350 \mathrm{~s}$, two keen-edged current decrease were immediately observed for Pt/ $\mathrm{C}$ catalyst, suggesting the poisoning of $\mathrm{Pt} / \mathrm{C}$ catalyst. Whereas, no visible change was observed for G-PDA-1, indicating its excellent property of methanol tolerance and its potential application in DMFC.

\section{Conclusions}

In summary, we present a novel G-PDA catalyst with high activity towards ORR, which were synthesized by in situ polymerization of dopamine on the surface of GO. As evidenced by structure characterizations, the strong interaction occurs between GO and PDA, inducing a variety of N-containing active sites towards ORR. Electrochemical measurements demonstrated that G-PDA-1 exhibited excellent catalytic activity towards ORR, in terms of onset potential, number of electron transferred and limiting current density, which was comparable to the commercial $20 \mathrm{wt} \% \mathrm{Pt} / \mathrm{C}$ catalyst. Both the G-PDA catalyst proposed in this work and the energy-saving strategy used to synthesize G-PDA are very significant to developing advanced ORR catalysts.

\section{Conflicts of interest}

There are no conflicts to declare. 


\section{Acknowledgements}

This work was financially supported by National Natural Science Foundation of China (21476264), Taishan Scholar Foundation (tsqn20161017, ts20130929), and Fundamental Research Funds for the Central Universities (18CX05007A, 15CX08009A).

\section{Notes and references}

1 M. S. Balogun, W. Qiu, Y. Luo, H. Meng, W. Mai, A. Onasanya, T. Olaniyi and Y. Tong, Nano Res., 2016, 9, 2823-2851.

2 C. Hu and L. Dai, Angew. Chem., Int. Ed., 2016, 55, 1173611758.

3 J. B. Goodenough, Acc. Chem. Res., 2012, 46, 1053-1061.

4 Y. Wang, K. S. Chen, J. Mishler, S. C. Cho and X. C. Adroher, Appl. Energy, 2011, 88, 981-1007.

5 D. Yan, Y. Li, J. Huo, R. Chen, L. Dai and S. Wang, Adv. Mater., 2017, 29, 1606459-1606479.

6 K. Li, Y. Li, Y. Wang, F. He, M. Jiao, H. Tang and Z. Wu, J. Mater. Chem. A, 2015, 3, 11444-11452.

7 S. Sugawara, K. Tsujita, S. Mitsushima, K. Shinohara and K. I. Ota, Electrocatalysis, 2011, 2, 60-68.

8 Y. Shao, J. Liu, Y. Wang and Y. Lin, J. Mater. Chem., 2009, 19, 46-59.

9 W. M. Wang, Z. L. Li, Z. Zou, H. Yang and S. Feng, ECS Trans., 2008, 16, 613-619.

10 K. Gong, F. Du, Z. Xia, M. Durstock and L. Dai, Science, 2009, 323, 760-764.

11 C. Venkateswara Rao and Y. Ishikawa, J. Phys. Chem. C, 2012, 116, 4340-4346.

12 G. Wu, N. H. Mack, W. Gao, S. Ma, R. Zhong, J. Han, J. K. Baldwin and P. Zelenay, ACS Nano, 2012, 6, 9764-9776.

13 S. Chen, J. Bi, Y. Zhao, L. Yang, C. Zhang, Y. Ma, Q. Wu, X. Wang and Z. Hu, Adv. Mater., 2012, 24, 5593-5597.

14 J. Xu, S. Lu, X. Chen, J. Wang, B. Zhang, X. Zhang, C. Xiao and S. Ding, Nanotechnology, 2017, 28, 485701.

15 Y. Zhao, L. Yang, S. Chen, X. Wang, Y. Ma, Q. Wu, Y. Jiang, W. Qian and Z. Hu, J. Am. Chem. Soc., 2013, 135, 1201-1204.

16 M. Chisaka, T. Iijima, Y. Ishihara, Y. Suzuki, R. Inada and Y. Sakurai, Electrochim. Acta, 2012, 85, 399-410.

17 L. Zhang, J. Niu, M. Li and Z. Xia, J. Phys. Chem. C, 2014, 118, 3545-3553.

18 L. Chen, X. Cui, Y. Wang, M. Wang, R. Qiu, Z. Shu, L. Zhang, Z. Hua, F. Cui, C. Wei and J. Shi, Dalton Trans., 2014, 43, 3420-3423.

19 D. S. Yang, D. Bhattacharjya, S. Inamdar, J. Park and J. S. Yu, J. Am. Chem. Soc., 2012, 134, 16127-16130.

20 S. K. Ramasahayam, U. B. Nasini, V. Bairi, A. U. Shaikh and T. Viswanathan, RSC Adv., 2014, 4, 6306-6313.

21 F. Razmjooei, K. P. Singh, M. Y. Song and J. S. Yu, Carbon, 2014, 78, 257-267.

22 H. Wu, L. Shi, J. Lei, D. Liu, D. Qu, Z. Xie, X. Du, P. Yang, X. Hu, J. Li and H. Tang, J. Power Sources, 2016, 323, 90-96.

23 Z. Jiang, X. Zhao, X. Tian, L. Luo, J. Fang, H. Gao and Z. J. Jiang, ACS Appl. Mater. Inter., 2015, 7, 19398-19407.
24 L. Qu, Y. Liu, J. B. Baek and L. Dai, ACS Nano, 2010, 4, 13211326.

25 Z. H. Sheng, L. Shao, J. J. Chen, W. J. Bao, F. B. Wang and X. H. Xia, ACS Nano, 2011, 5, 4350-4358.

26 L. Lai, J. R. Potts, D. Zhan, L. Wang, C. K. Poh, C. Tang, H. Gong, Z. Shen, J. Lin and R. S. Ruoff, Energy Environ. Sci., 2012, 5, 7936-7942.

27 Y. Tang, S. C. Burkert, Y. Zhao, W. A. Saidi and A. Star, J. Phys. Chem. C, 2013, 117, 25213-25221.

28 D. Yu, Q. Zhang and L. Dai, J. Am. Chem. Soc., 2010, 132, 15127-15129.

29 Y. Li, T. Li, M. Yao and S. Liu, J. Mater. Chem., 2012, 22, 10911-10917.

30 X. Zhou, Z. Yang, H. Nie, Z. Yao, L. Zhang and S. Huang, J. Power Sources, 2011, 196, 9970-9974.

31 L. Dai, Y. Xue, L. Qu, H. J. Choi and J. B. Baek, Chem. Rev., 2015, 115, 4823-4892.

32 H. F. Wang, C. Tang and Q. Zhang, Catal. Today, 2018, 301, 25-31.

33 L. Lai, J. R. Potts, D. Zhan, L. Wang, C. K. Poh, C. Tang, H. Gong, Z. Shen, J. Lin and R. S. Ruoff, Energy Environ. Sci., 2012, 5, 7936-7942.

34 Z. Lin, M. K. Song, Y. Ding, Y. Liu, M. Liu and C. P. Wong, Phys. Chem. Chem. Phys., 2012, 14, 3381-3387.

35 Z. Chen, D. Higgins, H. Tao, R. S. Hsu and Z. Chen, J. Phys. Chem. C, 2009, 113, 21008-21013.

36 Z. Yi, Z. Zhang, S. Wang and G. Shi, J. Mater. Chem. A, 2017, 5, 519-523.

37 D. Wei, Y. Liu, Y. Wang, H. Zhang, L. Huang and G. Yu, Nano Lett., 2009, 9, 1752-1758.

38 X. Li, H. Wang, J. T. Robinson, H. Sanchez, G. Diankov and H. Dai, J. Am. Chem. Soc., 2009, 131, 15939-15944.

39 S. Wang, D. Yu, L. Dai, D. W. Chang and J. B. Baek, ACS Nano, 2011, 5, 6202-6209.

40 K. Ai, Y. Liu, C. Ruan, L. Lu and G. M. Lu, Adv. Mater., 2013, 25, 998-1003.

41 K. N. Wood, R. O'Hayre and S. Pylypenko, Energy Environ. Sci., 2014, 7, 1212-1249.

42 W. S. Hummers Jr and R. E. Offeman, J. Am. Chem. Soc., 1958, 80, 1339.

43 D. C. Marcano, D. V. Kosynkin, J. M. Berlin, A. Sinitskii, Z. Sun, A. Slesarev, L. B. Alemany, W. Lu and J. M. Tour, ACS Nano, 2010, 4, 4806-4814.

44 M. A. Worsley, T. Y. Olson, J. R. Lee, T. M. Willey, M. H. Nielsen, S. K. Roberts, P. J. Pauzauskie, J. Biener, J. H. Satcher and T. F. Baumann, J. Phys. Chem. Lett., 2011, 2, 921-925.

45 L. Guo, Q. Liu, G. Li, J. Shi, J. Liu, T. Wang and G. Jiang, Nanoscale, 2012, 4(19), 5864-5867.

46 X. Yu, H. Wang, L. Guo and L. Wang, Chem.-Asian J., 2014, 9(11), 3221-3227.

47 L. B. Xing, S. F. Hou, J. Zhou, S. Li, T. Zhu, Z. Li, W. Si and S. Zhuo, J. Phys. Chem. C, 2014, 118(45), 25924-25930.

48 C. M. Parnell, B. Chhetri, A. Brandt, F. Watanabe, Z. A. Nima, T. K. Mudalige, A. S. Biris and A. Ghosh, Sci. Rep., 2016, 6, 31415. 
49 D. Guo, R. Shibuya, C. Akiba, S. Saji, T. Kondo and J. Nakamura, Science, 2016, 351(6271), 361-365.

50 Z. H. Sheng, L. Shao, J. J. Chen, W. J. Bao, F. B. Wang and X. H. Xia, ACS Nano, 2011, 5, 4350-4358.
51 J. Liebscher, R. Mrówczyński, H. A. Scheidt, C. Filip, N. D. Hădade, R. Turcu, A. Bende and S. Beck, Langmuir, 2013, 29(33), 10539-10548. 